Journal of Energy and
Environmental Sustainability
Journal homepage : www.jees.in

\title{
Thermodynamic Analysis of Lignite Gasification in the Downdraft Gasifier
}

\author{
D. S. Upadhyay*, A. K. V. Sakhiya, K. R. Panchal, R. N. Patel \\ Mechanical Engineering Department, Institute of Technology, Nirma University, Ahmedabad, Gujarat 382 481, India
}

\section{A R T I C L E I N F O}

Received : 13 March 2018

Revised : 12 April 2018

Accepted : 22 April 2018

Keywords:

Lignite, Downdraft gasifier, Particle size,

Energy, Exergy

\author{
A B S T R A C T
}

Thermodynamic study such as energy and mass balance and exergy analysis were carried out for different particle sizes of lignite in present work. An atmospheric pressure $10 \mathrm{kWe}$ downdraft gasifier was used for the experimentation purpose. Six particle sizes of lignite such as 13-16 mm, 16-19 mm, 19$22 \mathrm{~mm}, 22-25 \mathrm{~mm}, 25-28 \mathrm{~mm}$ and $28-31 \mathrm{~mm}$ were identified for thermodynamic analysis. Mass balance closure and energy balance closure were found in the range of 0.95-1 and 0.90-0.95 respectively. Exergy efficiency remained in the range of $23.66 \%-29.64 \%$ for all selected particle sizes. Exergy efficiency was found to be at maximum with $22-25 \mathrm{~mm}$ lignite size.

\section{Introduction}

Energy is the most crucial component of infrastructure for the growth and welfare of a nation. For a developing country, about $70 \%$ population in India lives in villages. About $77 \%$ of those villages are getting unreliable or limited access and poor quality of power (http://www.recindia.nic.in/ ddugjy). The major problem occurring in electrification of villages is the high cost of supplying electricity due to considerable losses in transmission and distribution. Furthermore the cost of grid extension in remote areas is economically unfeasible.

India utilizes much diversified sources for electricity generation such as coal, natural gas, oil, hydro and nuclear power as conventional sources as well as wind, solar, and agriculture and domestic waste as nonconventional sources. Out of these diversified sources of the power generation, the share of electricity generation from coal was about $59.9 \%$ (http://www.cea.nic.in/reports/monthly/executivesummary/2017/ exe_summary-01.pdf). India has about 308.80 billion tonnes of coal reserves which is distributed across the states of Jharkhand, Odisha, Chhattisgarh, Madhya Pradesh, Telangana and Maharashtra. Lignite reserves, as per the Geological Survey of India, were estimated around 44.59 billion tonnes (http://coal.nic.in/sites/ uploadfiles/coal/files / coalupload /chap1AnnualReport1617en.pdf). But still the lignite resources is not exploited much due to its poor quality (high moisture content, high ash content and low calorific value) and stability issues occurring during storage [Mike et al., 2017].
Rural electrification is the key to socio-economic development of the nation. From various approaches that are taken to meet this shortcomings, the Distributed Decentralized Energy Generation (DDEG) has proven its capability to fulfil the need of clean and reliable power supply [Nidhi et al., 2014]. DDEG is able to meet the challenges like operation on low load factor, grid extension to remote areas, and low demand and consumption and can ease the burden for massive electrification. There are various technologies that can be opted for the DDEG projects such as Solar Photo Voltaic power generation (SPV), mini/micro hydro turbines, Internal Combustion based power generators, Gas engines/turbines coupled with biomass gasifier, etc. (http://www.worldenergy.org/ documents/ser_2010_report_1.pdf).

Out of all power generating sources, the gasifier coupled with IC engines/turbine has been one of the most promising way of addressing the rural electrification as well as exploitation of lignite resources. The viability of this system along with economic feasibility has been investigated in literatures [Vimal et al., 2014; Vimal et al., 2017; Tripathi et al., 1997]. The experiments were done on a pilot-scale downdraft gasifier of $10 \mathrm{kWe}$ capacity with lignite as a feedstock. The detailed design of gasifier, method of experiment, instrumentation and gasification mechanism is reported elsewhere [Vimal et al., 2014; Vimal et al., 2017]. The investigation of the feasibility of lignite as fuel in downdraft gasifier, the effect of particle size on the gas composition, and gas yield, and the effect of lignite and waste wood mixture on clinker formation and gas composition has already been done extensively in literature [Vimal et al., 2014; Vimal et al., 2017].

\footnotetext{
*Corresponding Author: darshit.upadhyay@nirmauni.ac.in, darshitupadhyay@yahoo.com
} 
The objective of the current work focuses on investigating the thermodynamic analysis of lignite as a feedstock for the gasifier with various particle sizes. The particle sizes on which the experiments were conducted are 13-16 mm, 16-19 mm, 19-22 mm, 22-25 mm, 25-28 mm and $28-31 \mathrm{~mm}$. The present case study is carried to show the profound effect of particle size in gasification process. A brief literature study shows that the particle size in downdraft gasifier is an important parameter to optimize the performance of gasification process [Vimal et al., 2014, Ravindranath et al., 1993; Yin et al., 2012; Feng et al., 2014]. In the present work, influence of different particle sizes of lignite in the downdraft gasifier in terms of mass balance, energy balance and exergy analysis is reported.

\section{Materials and Methods}

\subsection{Experimental setup}

The experiments were carried out on an atmospheric pressure pilotscale $10 \mathrm{~kW}_{\mathrm{e}}$ downdraft gasifier as shown in Figure 1. It consisted of a gasifier reactor and a gas conditioning system (water scrubber, saw dust filled surge tank and fabric filter) [Nidhi et al., 2014]. Vibration mechanism was installed to avoid bridging or channelling problem of fuel. Water was circulated by pump and nozzle was kept to increase kinetic energy of water. Due to the partial vacuum, gas was sucked from the gasifier reactor. The K type (Chromel-Alumel) thermocouples were used for measuring the temperature of various zones of the gasifier. The gas flow rate was measured using an orifice meter (error within $\pm 3 \mathrm{Nm}^{3} \mathrm{~h}^{-1}$ ). The gas sample analysis was carried out on gas chromatograph (GC 2010, Shimadzu) to measure concentration of $\mathrm{CO}, \mathrm{CO}_{2}, \mathrm{H}_{2}, \mathrm{~N}_{2}$ and $\mathrm{cH}_{4}$ gases.

Table 1 shows the design and sizing parameters of the current gasifier setup. The characteristics of lignite are mentioned in Table 2.

The fuel was feed through the top cover of the gasifier reactor. Electric motor was used to induce vibration inside the reactor which allowed the smooth flow of the fuel and air through the throat of the gasifier. The water pump and tank system was used for cleaning and conditioning of the gas coming out from the gasifier. The sawdust filled surge tank absorbed excessive moisture from the gas and also maintain the flowrate of the gas.

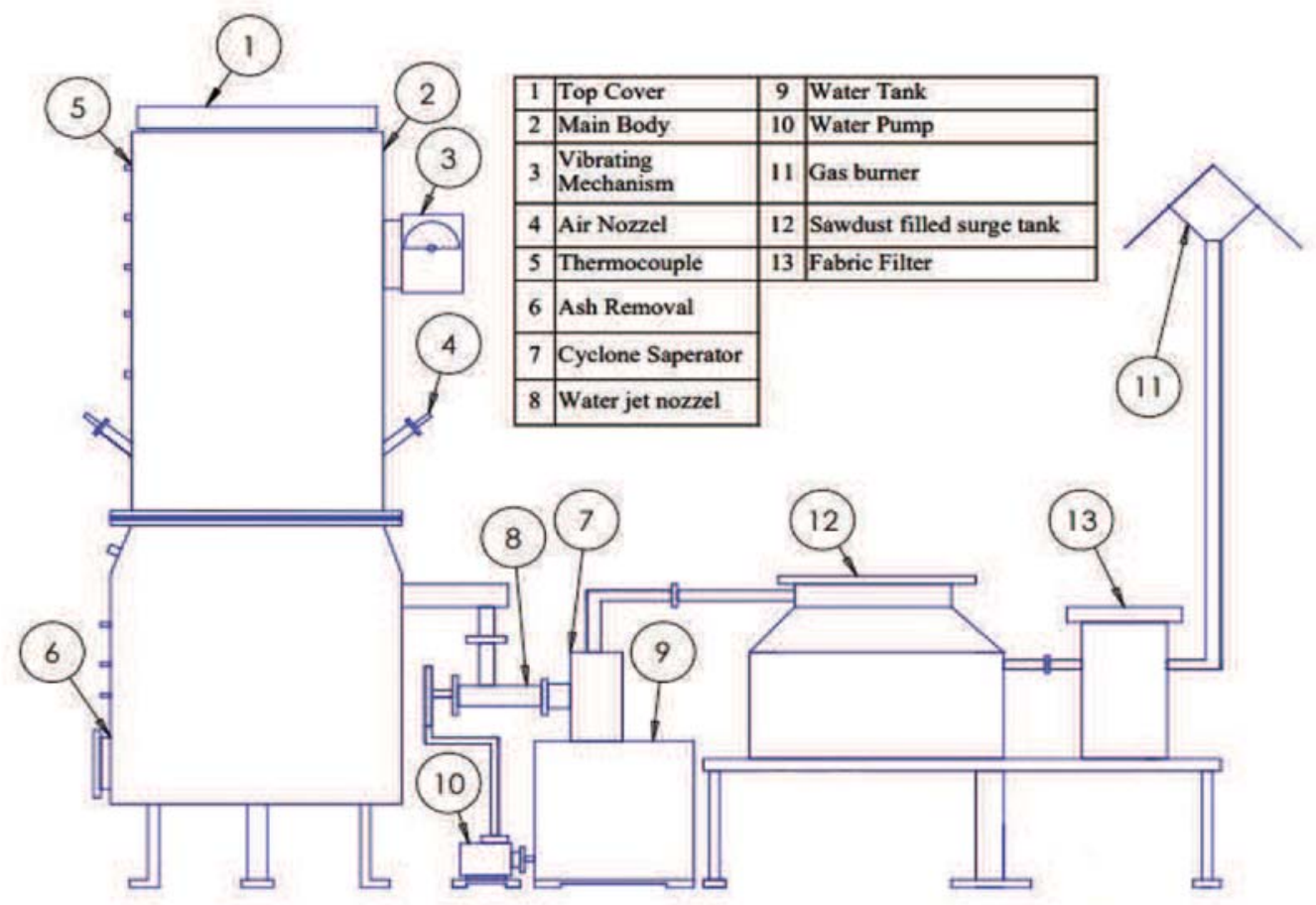

Figure 1 Layout of a pilot scale downdraft gasifier

Table 1 List of designed and sizing parameters

\begin{tabular}{|c|c|c|}
\hline Sr. No & Design and sizing Parameters & Specification \\
\hline 1 & Designed electrical output & $10 \mathrm{kWe}$ \\
\hline 2 & Assumed efficiency of engine & 0.33 \\
\hline 3 & Designed power consumption & $35.71 \mathrm{~kW}$ \\
\hline 4 & Assumed gasifier efficiency & 0.7 \\
\hline 5 & Designed Gas generation rate & 28.56 \\
\hline 6 & Lignite consumption rate of gasifier & $11.95 \mathrm{~kg} \mathrm{hr}^{-1}$ \\
\hline 7 & Designed gas yield per kg of fuel & $2.5 \mathrm{~m}^{3} \mathrm{~kg}^{-1}$ \\
\hline 8 & Dry fuel consumed divided by the surface area of the narrowest constriction. & 0.2 \\
\hline 9 & Throat area & $14300 \mathrm{~mm}^{2}$ \\
\hline 10 & Throat diameter & $135 \mathrm{~mm}$ \\
\hline 11 & Designed particle size & $22.5 \mathrm{~mm}$ \\
\hline 12 & Hopper diameter & $525 \mathrm{~mm}$ \\
\hline 13 & Height of hopper & $1100 \mathrm{~mm}$ \\
\hline 14 & Designed air flow rate & $13.5 \mathrm{~m}^{3} \mathrm{hr}^{-1}$ \\
\hline
\end{tabular}


Table 2 Characteristics of lignite

\begin{tabular}{|llll|}
\hline Analysis & Lignite & Analysis & Lignite \\
\hline Proximate $^{a}$ & & Ultimate $^{b}$ \\
Volatile matter $_{\text {Ash content }}$ & 42 & Carbon-C & 37.8 \\
Moisture & 15 & Hydrogen-H & 4.93 \\
Fixed carbon $^{c}$ & 12 & Nitrogen-N & 1.62 \\
Heating Value (MJ kg $^{-1}$ ) & 31 & Sulphur-S & 0.14 \\
\hline
\end{tabular}

a Test method IS 1350 (part-I)-1984

b Test method IS 1350 (part-II)-1970.

${ }^{\mathrm{c}}$ By difference.

After that, the gas was the passed through the dry fabric filter which removed the particulate matter and dust from the gases. Details of experimental setup, instrumentation and working procedure are also mentioned elsewhere [Vimal et al., 2014; Vimal et al., 2017]. The complete schematic diagram of the setup is shown in figure 1.

\subsection{Mass Balance}

The conservation of mass must be satisfied in the gasifier system. The mass balance was carried out by balancing the input mass to the gasifier with output masses from the gasifier. The input mass to the gasifier includes lignite and air as oxidizer, while the output mass to the gasifier includes mass of producer gas, ash, tar, char and water formed during the gasification process. The basic mass balance equation used for the gasification process is:

$$
m_{\text {fuel }}+m_{\text {air }}=m_{\text {gas }}+m_{\text {char }}+m_{\text {tar }}+m_{\text {ash }}+m_{\text {water }}
$$

Where, $\mathrm{m}_{\text {fuel }}$ and $\mathrm{m}_{\text {air }}$ in the above equation ( Eq. (1)) represents the fuel consumption rate of lignite and mass flow rate of air in a gasifier respectively. $\mathrm{m}_{\text {gas }}, \mathrm{m}_{\text {char, }} \mathrm{m}_{\text {tar, }} \mathrm{m}_{\text {ash }}$ and $\mathrm{m}_{\text {water }}$ represents the mass flow rate of producer gas, char, tar, ash and water formed in the gasification process respectively.

The fuel consumption was calculated by marking the initial position and final position of the feedstock and taking the bulk density of the feedstock $\left(776 \mathrm{~kg} / \mathrm{m}^{3}\right)$ measured using the test method IS $7190-1974$ [Vimal et al., 2014]. A hotwire anemometer with data logger was used to calculate the flow rate of air to the gasifier. The gas flow rate was calculated using the orifice meter within $\pm 3 \mathrm{Nm}^{3} \mathrm{~h}^{-1}$ or by using following equation:

$$
m_{\text {gas }}=\frac{m_{\text {fuel }} \times\left(\text { Gas yield }\left(\mathrm{Nm}^{3} \mathrm{~kg}^{-1}\right)\right)}{\text { Gas production time }(\mathrm{hr})}
$$

The mass of char and ash was measured by weighing the material formed at the bottom of the grate (ash pit) after the experiment. The mass of water represents the moisture content of producer gas. The moisture content in producer gas was calculated by using the vapour pressure of water vapour at atmospheric pressure and the average value of hourly recorded dry bulb temperature during the run. Due to the very low yield of tar in producer gas, it was neglected from the analysis.

\subsection{Energy Balance}

The Energy balance was carried out by using the following equation:

$E_{\text {fuel }}+E_{\text {air }}=E_{\text {gas }}+E_{\text {char }}+E_{\text {tar }}+E_{\text {ash }}+E_{\text {water }}+E_{\text {losses }}$

Where, $E_{\text {fuel }}$ and $E_{\text {air }}$ represents the energy inlet of a gasifier respectively, $E_{\text {gas }}, E_{\text {char }}, E_{\text {water }}$ and $E_{\text {losses }}$ represents the energy outlet from the gasifier.

The energy rate of the fuel was calculated using following equation:

$$
E_{\text {fuel }}=m_{\text {fuel }} \times L H V_{\text {fuel }}
$$

Where $m_{\text {fuel }}$ is the lignite consumption rate of the gasifier, $L H V_{\text {fuel }}$ is the lower heating value of lignite.

The energy content of the air flow was calculated using the equation (Eq. (5)):

$$
E_{\text {air }}=m_{\text {air }} \times C_{p \text { air }}\left(T_{\text {air }}-T_{\text {ref }}\right)
$$

Where, $m_{\text {air }}$ represents the mass flow rate of air and $C_{\text {pair }}$ is the specific heat of air, $T_{a i r}$ and $T_{r e f}(298.15 \mathrm{~K})$ are the inlet air temperature and reference temperature respectively.

Energy from the producer gas was obtained by the combined effect of chemical and physical energy of producer gas. Density of producer gas was calculated by using density of different gas compositions in producer gas at measured temperature and their composition. LHV of gas was calculated from the gas composition obtained by gas chromatograph (GC2010, Shimadzu) equipment as suggested in the literature [Vimal et al., 2014; Vimal et al., 2017, Reed 1988]. The total energy of producer gas includes the physical energy rates and its chemical energy rates. The following equation (Eq. (6)) was used to calculate the chemical energy rate of the producer gas:

$$
E_{\text {gas-chemical }}=m_{\text {gas }} \times \frac{L H V_{\text {gas }}}{\rho_{\text {gas }}}
$$

Where, $p_{g a s}$ represents the producer gas density, $L H V_{g a s}$ represents the heating value of producer gas.

The physical energy rate of producer gas was calculated using equation:

$$
E_{\text {gas-physical }}=m_{\text {gas }} \times h_{\text {gas }}
$$

Where, $h_{\text {gas }}$ is representing the specific enthalpy of producer gas.

The specific enthalpy of the producer gas was calculated by using the correlation (Eq. (8) or Eq. (9)) between enthalpies and mole fractions of the gas components i.e. $\mathrm{N}_{2}, \mathrm{H}_{2}, \mathrm{Co}_{2}, \mathrm{CH}_{4}$ and $\mathrm{CO}$ :

$$
h_{\text {gas }}=\sum_{i=1}^{n} h_{o i}+y_{i} h_{i}
$$

(or)

$$
h_{g a s}=\sum_{i=1}^{n} h_{o i}+y_{i} C p_{i} d T
$$

Where, $h_{o i}$ and $h_{i}$ represents the specific enthalpy of dead state and a specific temperature respectively for $i^{\text {th }}$ component of gas, $Y_{i}$ represents the mole fraction of various gas components and $C_{p i}$ represents the specific heat of various gas components. The equation used to calculate is:

$$
C_{p}=a+b T+c T^{2}+d T^{3}
$$

Where, the values of $a, b, c$ and $d$ are reported elsewhere [Cengel 1994].

The energy content of char was calculated using Eq. (11) and the energy rate of ash was calculated by using any of Eq. (12) and Eq. (13)

$$
\begin{aligned}
& E_{\text {char }}=m_{\text {char }} H H V_{\text {char }} \\
& E_{\text {ash }}=m_{\text {ash }} h_{\text {ash }}
\end{aligned}
$$

or

$$
E_{a s h}=m_{a s h} C_{p a s h} d T
$$

Where, $h_{a s h}$ and $C_{\text {pash }}$ are the specific enthalpy and specific heat of ash respectively. The specific heat capacity of ash was calculated using the following correlation:

$$
C_{p a s h}=K_{0}+K_{1} T^{-0.5}+K_{2} T^{-2}+K_{3} T^{-3}
$$

Where, the values coefficients of the Eq. (14) are reported in the literature [Dahlquist 2013].

\subsection{Exergy Balance}

Exergy analysis was carried out for the gasification process of lignite with different particle sizes. Based on the exergy analysis, the performance of gasifier system is optimize in terms of Exergy efficiency and Exergy destruction. 
Exergy efficiency or second law efficiency is defined as a ratio of exergy of the producer gas $\left(\phi_{\text {gas }}\right)$ to sum of exergy of Lignite $\left(\phi_{\text {lignite }}\right)$ and gasification medium $\left(\phi_{\text {medium }}\right)$. The equation used for calculating the second law efficiency as shown in (Eq. (15)):

$$
\eta_{\text {ex }}=\frac{\emptyset_{\text {gas }}}{\emptyset_{\text {lignite }}+\emptyset_{\text {medium }}}
$$

In current analysis, air was used as an oxidising medium. The air was supplied to the gasifier at atmospheric condition. Exergy of air was neglected as it was very less compared to fuel and gas exergy.

The total exergy of the producer gas is the sum of its thermomechanical and chemical exergy. Thermo-mechanical exergy is further classified into mechanical and thermo-mechanical exergy. Mechanical exergy includes sum of potential and kinetic exergy, while thermomechanical exergy can be decomposed into temperature and pressure based component. Kinetic and potential exergy are independent of temperature and pressure and hence it's been neglected in analysis. Chemical exergy includes the exergy from mixing \& separation and exergy from chemical reactions. [Truls 2009]

The total exergy of produces gas includes thermo-mechanical exergy and chemical exergy which is shown in the Eq. (16).

$$
\emptyset_{x, \text { gas }}=\emptyset_{x, t-\text { mech }}+\emptyset_{x, \text { chem }}
$$

The specific thermo-mechanical exergy for different gas species can be calculated using Eq. (17).

$$
\emptyset_{x, t-\text { mech }}=\left(h-h_{o}\right)-T_{o}\left(s-s_{o}\right)
$$

Where, $\mathrm{h}$ and s represents the enthalpy and entropy respectively at the specified temperature and specified pressure, while $h_{0}$ and $s_{o}$ are dead state enthalpy and entropy respectively $\left(\mathrm{T}_{0}=298.15 \mathrm{~K}, \mathrm{P}_{0}=1 \mathrm{~atm}\right.$.).

To calculate specific chemical exergy of ideal gas fluid, following Eq. (18) was used:

$$
\emptyset_{x, \text { chem }}=\sum_{i} x_{i} \emptyset_{c h, i}+R T_{o} \sum_{i} x_{i} \ln x_{i}
$$

Where, $x_{i}$ represents mole fraction of $i^{\text {th }}$ species and $R$ is the universal gas constant $\left(\mathrm{R}=8.314 \mathrm{~g} \mathrm{~mol}^{-1}\right), \phi_{c h, i}$ is standard chemical exergy of species in $k J$. The standard chemical exergy of various gases is reported in literature [Bejan 1996].

The standard specific chemical exergy of the lignite can be calculated using [Kotas 1985]:

$$
\emptyset_{\text {fuel }}=\left(L H V_{\text {fuel }}+2442 \times W_{\text {fuel }}\right) \beta
$$

Where, $L H V_{\text {fuel }}$ is the lower heating value of the lignite and $W_{\text {fuel }}$ is the mole fraction of the moisture present in the lignite, $\beta$ is the ratio of standard chemical exergy to LHV of the lignite which is expressed by:

$$
\beta=\frac{1.0438+0.1882 \frac{m_{H}}{m_{C}}-0.2509 \frac{m_{O}}{m_{C}}\left[1+0.7256 \frac{m_{H}}{m_{C}}\right]+0.383 \frac{m_{N}}{m_{C}}}{1-0,3035 \frac{m_{O}}{m_{C}}}
$$

\begin{tabular}{|c|c|c|c|c|c|c|c|c|c|}
\hline \multirow{2}{*}{$\begin{array}{c}\text { Particle } \\
\text { Sizes }(\mathbf{m m})\end{array}$} & \multicolumn{3}{|c|}{ Inputs $\left(\mathrm{kg} \mathrm{h}^{-1}\right)$} & \multicolumn{5}{|c|}{ Outputs ( $\left.\mathrm{kg} \mathrm{h}^{-1}\right)$} & \multirow{2}{*}{ MBC } \\
\hline & Fuel & Air & Total & Dry gas & Char & Water & Ash & Total & \\
\hline 13-16 & 10.67 & 18.31 & 28.98 & 24.86 & 0.30 & 1.80 & 1.65 & 28.61 & 0.98 \\
\hline 16-19 & 10.55 & 18.23 & 28.78 & 23.77 & 0.28 & 1.82 & 1.63 & 27.50 & 0.95 \\
\hline $19-22$ & 10.25 & 18.01 & 28.26 & 24.03 & 0.27 & 1.89 & 1.57 & 27.76 & 0.98 \\
\hline $22-25$ & 10.01 & 17.66 & 27.67 & 22.99 & 0.23 & 1.79 & 1.54 & 26.55 & 0.95 \\
\hline $25-28$ & 9.86 & 17.45 & 27.31 & 23.05 & 0.22 & 1.73 & 1.48 & 26.48 & 0.96 \\
\hline 28-31 & 9.72 & 17.10 & 26.82 & 23.14 & 0.15 & 1.68 & 1.46 & 26.43 & 0.98 \\
\hline
\end{tabular}

Where, $m_{H}, \mathrm{~m}_{\mathrm{c}}, \mathrm{m}_{\mathrm{o}}$ and $\mathrm{m}_{\mathrm{N}}$ are mass fraction of substances of which is shown in Table (3).

Table 3 The mass balance of the lignite gasification with various particle sizes.

"MBC means Mass Balance Closure
Another important parameter for exergy analysis of lignite gasification is exergy destruction. Exergy destruction was found by exergy balance as shown below [Shayana et al., 2018].

$$
\emptyset_{\text {destruction }}=\sum \emptyset_{\text {in }}-\sum \emptyset_{\text {out }}
$$

Where, $\phi_{\text {destruction }}, \phi_{\text {in }}$ and $\phi_{\text {out }}$ are the exergy destruction, inlet exergy and outlet exergy respectively. The total inlet exergy is the sum of exergies of the medium and exergy of fuel while the outlet exergy is the exergy of producer gas leaving out.

\section{Results and discussion}

\subsection{Mass Balance}

The mass balance for different particle sizes viz. 13-16 mm, 16-19 $\mathrm{mm}, 19-22 \mathrm{~mm}, 22-25 \mathrm{~mm}, 25-28 \mathrm{~mm}$ and $28-31 \mathrm{~mm}$ is shown in Table 3 .

Mass of lignite and air mixture was taken as input whereas mass of dry gas, char, water and ash were taken as output in gasification process. Generally the mass of tar content in producer gas is very less compared to other constituents in the output, hence it was neglected. Mass of fuel, air and dry gas were decreased as particle size increased. It is due to the fact that smaller particle size has higher surface area which may react with larger quantity of air. Water content in producer gas with all particle sizes was not uniform. It is because of different relative humidity content during various experiments. The ash content per $\mathrm{kg}$ of lignite was assumed to be constant. Ash content in the output is only dependent on the fuel consumption. It was observed that ash content reduced with the increment of particle size of lignite as the fuel consumption decreased. Char content also reduced with increase in the particle size of lignite. For small particle size of lignite, the fuel easily escaped to the reduction zone. MBC ratios for all selected size of lignite were found in the range of 0.95 to 1 .

\subsection{Energy balance}

Input and output energies for different particle size of lignite along with energy balance closure (EBC) are shown in Table 4. Energy of fuel is depending on LHV and fuel consumption rate only. As per kg of lignite LHV remained same for different particle size, hence energy rate of fuel depends only on fuel consumption. Generally the large particle size of fuel exhibits low rate of combustion [Ruy et al., 2006; Renzhan et al., 2012]. Due to this more time was taken by the fuel for the complete combustion. From table 4 it can be seen that the energy of fuel keeps on decreasing as the particle size increases. This is the result of low rate of fuel combustion. Energy of producer gas is dependent on the LHV of the fuel and gas yield. The LHV of the fuel kept on increasing [Vimal et al., 2014] as the particle size increased and was maximum for particle size $22-25 \mathrm{~mm}$ and then decreased on further increase in particle size. The gas yield kept increasing for increasing in particle size [Vimal et al., 2014]. Hence the energy of producer gas was increasing of lower particle sizes and then kept decreasing as the particle size was further increased. It can be seen that the highest energy of producer gas was achieved by the particle size $16-19 \mathrm{~mm}$ and not with $22-25 \mathrm{~mm}$ size. However energy input by fuel was higher for particle size $16-19 \mathrm{~mm}$ compared to $22-25$ $\mathrm{mm}$. Hence the thermal efficiency of $22-25 \mathrm{~mm}$ was found highest compared to other particle size of lignite. Energy of air is dependent on mass and specific velocity of airflow as well as the air temperature. Variation in air temperature was observed as different experiments were conducted on different days. It was observed that the energy from ash was higher for smaller sizes of lignite. ECB ratio was found in the range of 0.90 to 0.95 .

\subsection{Exergy analysis}

Exergy destruction, fuel feed rate and exergy efficiency for different particle size of lignite are as shown in figure 3. Exergy of fuel is dependent of the fuel composition. Exergy of fuel for different particle sizes of lignite remain constant as exergy of fuel is independent of particle size and the fuel composition was fairly same throughout the experimental run. It can be observed from figure 3 that the exergy efficiency keeps on increasing for particle size from $13-16 \mathrm{~mm}$ to particle size $22-25 \mathrm{~mm}$ and achieves maximum value for particle size of range $22-25 \mathrm{~mm}$ of about $29.64 \%$. The exergy efficiency can be observed to have decreased for further increase in particle size. Exergy efficiency was calculated and was in the range of $23.66 \%-29.64 \%$ for all selected particle sizes of lignite. The exergy destruction was also calculated for different range of particle sizes. Exergy destruction shows the amount of energy that was wasted in the gasification process. Figure 3 shows that the total exergy destruction was decreasing as the particle size was increased from 13-16 mm and was minimum for particle size $22-25 \mathrm{~mm}$ and it was $413.46 \mathrm{~kW}$. On further 
Table 4 The energy balance of lignite gasification

\begin{tabular}{|c|c|c|c|c|c|c|c|c|c|}
\hline \multirow{2}{*}{$\begin{array}{c}\text { Particle } \\
\text { Size } \\
\text { mm) }\end{array}$} & \multicolumn{2}{|c|}{$\begin{array}{c}\text { Energy in } \\
\text { (MJ/hr) }\end{array}$} & \multicolumn{6}{|c|}{ Energy Out (MJ/hr) } & \multirow{2}{*}{$\begin{array}{c}\text { EBC }^{* *} \\
\%\end{array}$} \\
\hline & Fuel & Air & Input & Producer Gas & Char & Ash & Water & Output & \\
\hline $13-16$ & 164 & 0.257 & 154.0 & 137.54 & 3.64 & 0.125 & 3.34 & 144.6 & 93.9 \\
\hline $16-19$ & 162 & 0.293 & 162.2 & 139 & 3.65 & 0.123 & 4.01 & 146.7 & 90.4 \\
\hline $19-22$ & 157.44 & 0.271 & 159.8 & 136.36 & 3.34 & 0.119 & 5.01 & 144.8 & 90.5 \\
\hline $22-25$ & 153.75 & 0.257 & 154.0 & 134.60 & 3.17 & 0.117 & 4.59 & 142.4 & 92.5 \\
\hline $25-28$ & 151.44 & 0.243 & 151.6 & 128.93 & 5.23 & 0.112 & 3.72 & 137.9 & 90.9 \\
\hline $28-31$ & 149.3 & 0.242 & 149.5 & 126.23 & 4.91 & 0.110 & 3.73 & 134.9 & 90.2 \\
\hline
\end{tabular}

"EBC means Energy Balance Closure

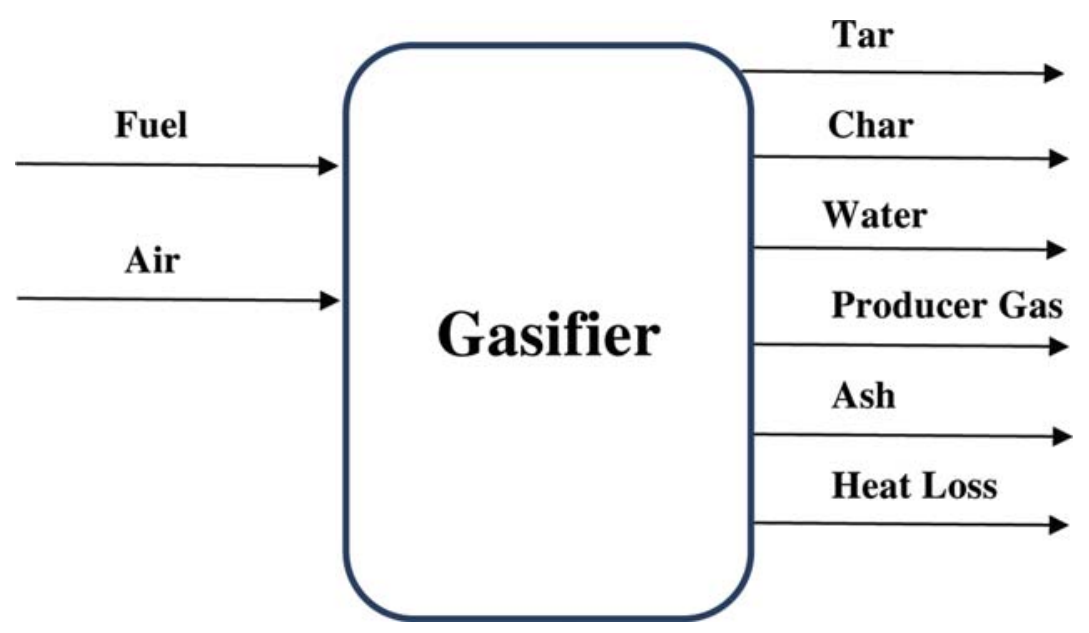

Figure 2 Gasifier inputs and products

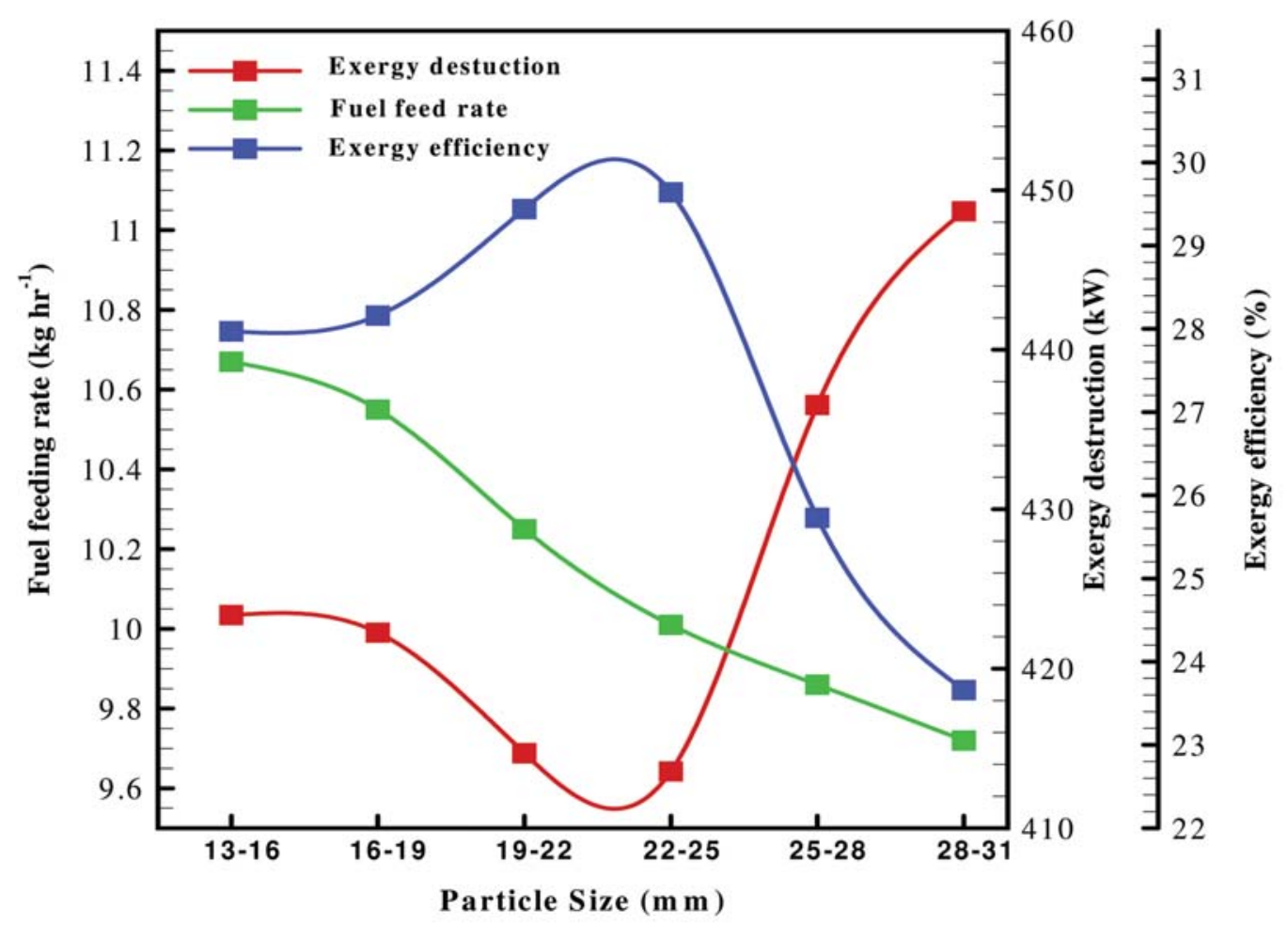

Figure 3 Exergy destruction, fuel feed rate and exergy efficiency for various particle size of lignite 
increasing the particle size the exergy destruction was increased. While comparing the exergy destruction with exergy efficiency, the higher value of exergy destruction corresponds to the lower values of exergy efficiency and vice versa. This inference was inline with the analysis done in by [Shayana et al., 2018].

Thermo-mechanical efficiency is generally dependent on enthalpy and entropy of the producer gas. The temperature achieved in the oxidation zone is responsible for the producer gas temperature. The smaller particle size of lignite burned easily compared to bigger particle size, hence more heat was released in the oxidation zone due to smaller particle size of lignite. It was responsible for higher thermo-mechanical exergy for particle size of 13-16 mm and lesser thermo-mechanical exergy for 28-31 mm lignite size. Chemical exergy was generally depending on exergy of individual producer gas species. As combustible product such as $\mathrm{H}_{2}, \mathrm{CO}$ in producer was higher with $22-25 \mathrm{~mm}$ lignite feedstock [Vimal et al., 2014], its chemical exergy was found higher comparatively. The variations of thermo-mechanical and chemical exergy for various particle sizes are shown in figure 4.

Thermo-mechanical and chemical exergy curves were intersected on 22-25 mm lignite size, shown optimum particle size lignite among selected particle sizes of lignite. This result was in line with higher exergy efficiency as per figure 3 and higher cold gas efficiency [Vimal et al., 2014] for 22$25 \mathrm{~mm}$ lignite size.

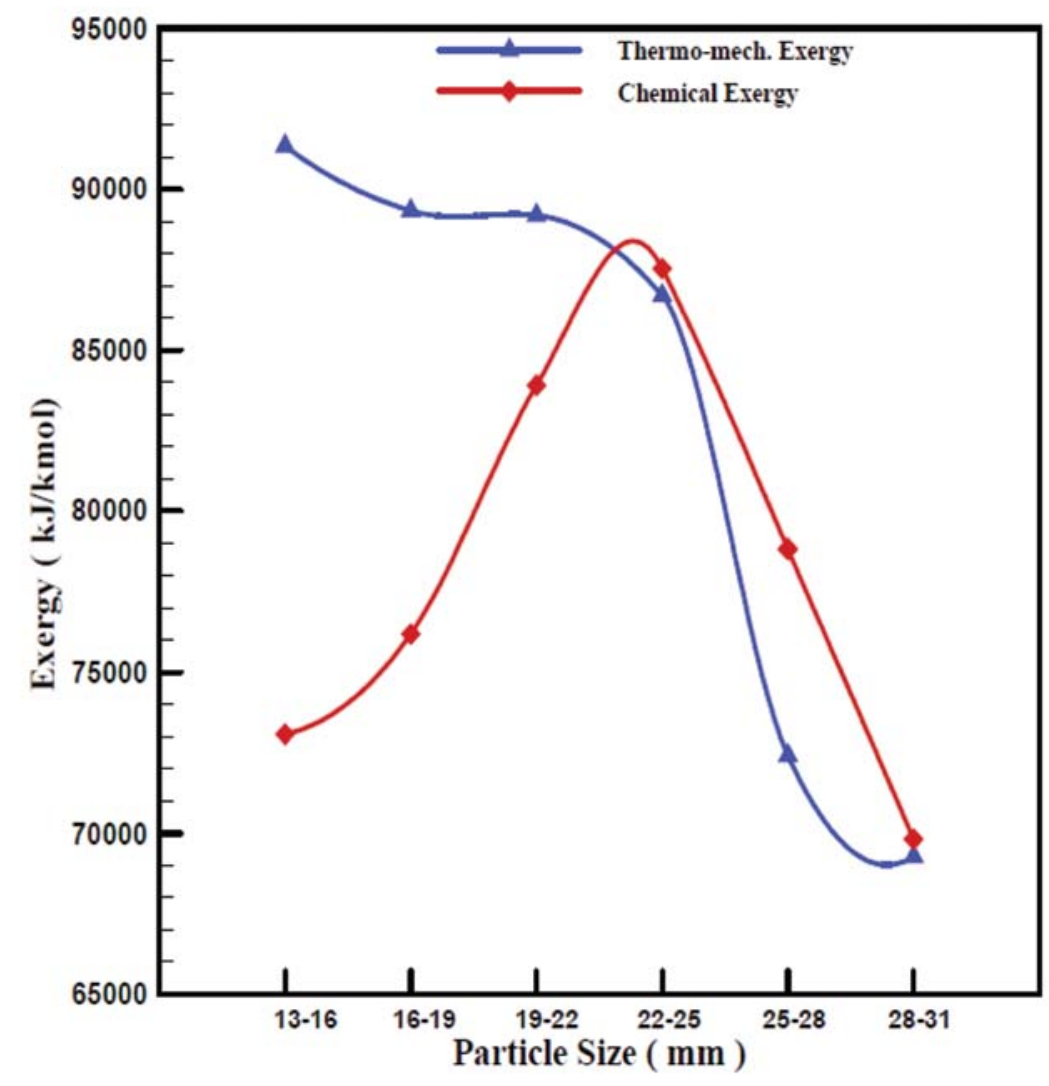

Figure 4: Thermo-mechanical and chemical energy of different particle size of lignite

\section{Conclusion}

The thermodynamic analysis was carried out in the downdraft gasifier. Six different particle sizes (13-16 mm, 16-19 mm, 19-22 mm, 22-25 mm, $25-28 \mathrm{~mm}, 28-31 \mathrm{~mm}$ ) of lignite were taken into consideration for the thermodynamic analysis. Mass balance and Energy balance were carried out for all selected particle sizes of lignite. Exergy destruction and exergy efficiency were calculated for various particle sizes. Following results are found from the analysis:

- Closure ratio of energy and mass balance were found in the range of $0.90-0.95$ and $0.95-1$ respectively.

- Exergy efficiency for all the particle sizes varied in the range of 23.66 $\%-29.64 \%$.

- The $22-25 \mathrm{~mm}$ particle size of lignite had the maximum exergy efficiency among all the selected feedstocks.

- Exergy destruction first decreased with increment in particle size from $13-16 \mathrm{~mm}$ and it was found minimum for the particle size of 22-25 $\mathrm{mm}$. Then the exergy destruction increased for further increment in the particle sizes.

- The exergy destruction was found in the range of $413.56 \mathrm{~kW}$ and $448.69 \mathrm{~kW}$. For $22-25 \mathrm{~mm}$ particle size the exergy destruction was minimum i.e. $413.46 \mathrm{~kW}$.

\section{Acknoledgement}

Authors are thankful to Dr. Vimal R Patel and Dr. Femina J Patel for giving valuable suggestions in thermodynamic analysis.

\section{References}

Bejan A, Tsatsaronis G, Moran M. (1996), Thermal design and optimization, Wiley \& Sons, New York, USA.

Cengel YA, Boles MA (1994), Thermodynamics: an engineering approach, McGrawHill, Inc, New York, USA.

Dahlquist E (2013), Technologies for converting biomass to useful energy: combustion, gasification, pyrolysis, Torrefaction and fermentation, series of Sustainable energy development (4), CRC press, Florida, USA.

E. Shayana, V. Zareb, I. Mirzaeea, et al (2018), Hydrogen production from biomass gasification; a theoretical comparison of using different gasification agents. Energy conservation and management, 159:30-41.

Feng Yu, et al (2014), Influence of particle size and temperature on gasification performance in externally heated gasifier. Smart Grid Renew Energy, 2:158-164.

Kotas TJ (1985), The exergy method of thermal plant analysis. Butterworths, London.

Mike CF, Theovan L, et al (2017), A review of the history of coal exploration, discovery and production in Indonesia: The interplay of legal framework, coal geology and exploration strategy, International Journal of Coal Geology, 178:56-73.

Nidhi Verma, et al (2014), Scenario of Rural Electrification in India- Challenges and Impact, Int. Journal of Engineering Research and Applications, 4:39-43. 
Patel VR, D. S. Upadhiyay, R. N. Patel (2014), Gasification of lignite in a fixed bed reactor: Influence of particle size on performance of downdraft gasifier, Journal of Energy, 78:323-332.

Patel VR, D. S. Upadhiyay, R. N. Patel (2017), Co-gasification of lignite and waste wood in a pilot-scale (10 kWe) downdraft gasifier, Journal of Energy, 119:834-844.

Ravindranath NH, et al (1993), Biomass gasification: environmentally sound technology for decentralized power generation, a case study from India, Journal of Biomass Bio- energy, 4:49-60.

Reed TB, Das A (1988), Handbook of biom ass downdraft gasifier engine systems. SERI, Colorado, USA.

Renzhan Yin, et al (2012), Influence of particle size on performance of a pilot-scale fixedbed gasification system, Bioresource Technology, 119:15-21.

Ryu, C., Yang, et al (2006), Effect of fuel properties on biomass combustion: Part I. Experiments-fuel type, equivalence ratio and particle size, Fuel, 85:1039-1046.
Tripathi AK, Iyer PVR, Kandpal TC (1997), A financial evaluation of biomass-gasifierbased power generation in India, Journal of Bioresour Technol, 61:53-59.

Truls Gundersen (2009), The introduction to the concept of exergy and energy quality, Springer, Norway.

Yin Renzhan, et al (2012), Influence of particle size on performance of a pilot-scale fixedbed gasification system. Journal of Bioresource Technology, 119:15-21.

http://www.recindia.nic.in/ddugjy; Accessed on: 24 Dec. 2017.

http://www.cea.nic.in/reports/monthly/executivesummary/2017/exe_summary-01.pdf; Accessed on: 1 Jan. 2018.

http://coal.nic.in/sites/ uploadfiles/coal/files /coalupload /chap1AnnualReport1617en. pdf; Accessed on: 12 Jan. 2017.

http://www.worldenergy.org/documents/ser_2010_report_1.pdf; Accessed on: 2 Feb. 2018. 